\title{
Evaluation of Metabolic and Hydroelectrolytic Disturbances in Patients Diagnosed with Diabetic Ketoacidosis
}

\author{
MARIANA CORNELIA TILINCA ${ }^{1}$, CSILLA NANIA ${ }^{1}$, SANDOR PAL $^{2 *}$, RALUCA TILINCA $^{1}$, \\ MONIKA SZABO ${ }^{1}$, ENIKO NEMES-NAGY ${ }^{3}$ \\ ${ }^{1}$ UMPhST Tirgu Mures, Faculty of Medicine, 38 Gh. Marinescu Str., 540139, Tirgu Mures, Romania \\ ${ }^{2}$ University of Pecs, Clinical Centre, Neurology Clinic, 7633, Pécs, Rét str. 2 \\ ${ }^{3}$ UMPhST Tirgu Mures, Faculty of Pharmacy, 38 Gh. Marinescu Str., 540139, Tirgu Mures, Romania
}

\begin{abstract}
Ketoacidosis is a life-threatening complication of diabetes mellitus, especially type 1 diabetic patients being predisposed to this condition. Ketoacidosis might occur also in other types of diabetes triggered by circumstances leading to shortage of insulin. The aim of the study was the assessment of metabolic, hydroelectrolytic disturbances and the relationship between different parameters in patients hospitalized with diabetic ketoacidosis. We evaluated the clinical state, parameters of blood-gas analyzer, biochemistry and hematology laboratory results of 32 patients admitted with diabetic ketoacidosis between January-November 2018 at the Department of Diabetology, Nutrition and Metabolic Diseases of the Emergency County Hospital in Tîrgu Mureș. Demographic data, associated diseases, body mass index were also evaluated. The considered threshold of significance was 0.05. The distribution of type 1 and 2 diabetes was 40.6 and $46.9 \%$ in the studied group, $53.1 \%$ being male patients. Positive correlation could be observed between $\mathrm{pH}$ and base excess and between $\mathrm{pH}$ and bicarbonate values, while negative correlation could be found between triglyceridemia and body mass index (BMI). Severe hyperglycemia, very low pH values, glucosuria, ketonuria and electrolytic imbalances were very common in the studied patients. Pancreatitis, respiratory tract and urinary infections could be found in the background of ketoacidotic manifestations in the majority of the patients, dehydration occured in each of the cases. Many severe metabolic and hydroelectrolytic disturbances could be observed in the studied patients presenting diabetic ketoacidosis. Infectious diseases are the most common triggers of metabolic imbalance in diabetic patients.
\end{abstract}

Keywords: diabetic ketoacidosis, blood-gas analyzer, metabolic parameters

The incidence of diabetes mellitus shows a growing tendency worldwide [1]. In Romania the prevalence diabetes is $11.6 \%$ in the population according to PREDATORR study [2], and it's a high number of undiagnosed cases which significantly surcharges the budgetary effort of the public health care system. [3] Unhealthy diet, sedentary lifestyle and intense stress exposure contribute to the huge number of diabetic individuals [4].

Diabetic ketoacidosis is a severe, potentially life-threatening complication of diabetes mellitus, characterized by elevated circulating ketones, and the development of ketoacidosis under hyperglycemic conditions due to insulin deficiency [5]. Especially type 1 diabetic patients are predisposed to ketoacidosis, in these cases an absolute insulin deficiency occurs on autoimmune background, the manifestation can be with or withour other associated diseases having similar mechanism [6]. According to recent statistics, Diabetic ketoacidosis can also occur in patients having type 2 , secondary or other types of diabetes, triggered by infectious diseases, steroid medication or other states leading to shortage of insulin.

Several laboratory parameters can contribute to the proper diagnosis and management of the metabolic and hydroelectrolytic disturbances which commonly occur in this condition. Mild hypertriglyceridemia is frequent in diabetic ketoacidosis, severe elevation of serum triglycerides can lead to acute pancreatitis [7]. Determination of blood gas analyses is essential in diabetic ketoacidosis, prolonged monitoring of these parameters and the use of sodium bicarbonate is controversial in patients having $p \mathrm{H}$ over $7[8,9]$. Proper management of diabetic ketoacidosis includes administration of fluids because of dehydration, insulin treatment and electrolyte replacement [10].

\section{Experimental part}

Material and methods

In our retrospective study a number of 32 diabetic ketoacidotic patients' data was processed, who were hospitalized by emergency admission in the Department of Diabetology, Nutrition and Metabolic Diseases of the Emergency 
*email: palssandor@outlook.com

County Hospital in Tirgu Mures, between January-November 2018. Paraclinical and laboratory test results were collected among the assessed data regarding associated diseases.

The laboratory analyses were performed in the Central Laboratory of the Emergency Clinical County Hospital in Tirgu Mures, blood-gas analysis of the patients was performed by the Emergency Department UPU. The metabolic investigation of the patients included the routine laboratory analyses: serum glucose, total cholesterol, triglycerides, total bilirubin, amylase and transaminase activity. Other biochemical parameters that were assessed are: serum urea, creatinine, sodium, potassium, chloride, calcium, total protein and urine strip test results. The Cobas 6000 analyzer was used to perform the biochemical analyses of the admitted patients, pathological urine compounds were determined by reflectometry.

Statistical analysis of the obtained data was performed by the GraphPad InStat software. The significance threshold was set to a $\mathrm{p}$ value under 0.05 .

\section{Results and discussions}

The studied group had an average age of $51.21+/-14.78$ (SD) years, and $46.9 \%$ of them were female. The mean BMI was $25.92 \mathrm{~kg} / \mathrm{m}^{2}+/-4.75$ (SD), $50 \%$ of the patients had high BMI $\left(>25 \mathrm{~kg} / \mathrm{m}^{2}\right)$, and $18.75 \%$ of them were obese $\left(\mathrm{BMI}>30 \mathrm{~kg} / \mathrm{m}^{2}\right.$ ). Average duration of hospitalization was $9.09+/-3.70$ (SD) days. $40.6 \%$ of the patients were type 1 diabetic individuals, $46.9 \%$ were diagnosed with type 2 diabetes and $12.5 \%$ with secondary diabetes. $31.3 \%$ of the subjects were new cases, recently diagnosed in ketoacidotic state.

The mean values and standard deviations of the patients' main important parameters are represented in Table 1.

Table 1

REPRESENTATION OF MEAN AND STANDARD DEVIATIONS OF THE ANALYZED PARAMETERS

\begin{tabular}{|c|c|c|}
\hline Parameter & Mean value & Standard deviation \\
\hline Venous $\mathrm{pH}$ & 7.18 & 0.12 \\
\hline Venous $\mathrm{pCO}_{2}(\mathrm{mmHg})$ & 28.31 & 8.87 \\
\hline Venous $\mathrm{pO}_{2}(\mathrm{mmHg})$ & 45.54 & 22.27 \\
\hline Base Excess (mmol/l) & -15.525 & 6.90 \\
\hline Serum glucose $(\mathrm{mg} / \mathrm{dL})$ & 622.37 & 250.77 \\
\hline Lactate $(\mathrm{mg} / \mathrm{dL})$ & 20.13 & 11.81 \\
\hline Sodium $(\mathrm{mEq} / \mathrm{L})$ & 132.53 & 6.28 \\
\hline Potassium $(\mathrm{mEq} / \mathrm{L})$ & 4.43 & 0.90 \\
\hline Chlorine $(\mathrm{mEq} / \mathrm{L})$ & 104.59 & 9.52 \\
\hline Calcium $(\mathrm{mmol} / \mathrm{L})$ & 0.98 & 0.25 \\
\hline Bicarbonate $(\mathrm{mEq} / \mathrm{L})$ & 12.38 & 4.53 \\
\hline Leucocytes $\left(\mathrm{x} 10^{3} / \mu \mathrm{L}\right)$ & 15.18 & 8.567 \\
\hline Hematocrit $(\%)$ & 41.27 & 7.27 \\
\hline Hemoglobin $(\mathrm{g} / \mathrm{dL})$ & 13.82 & 2.79 \\
\hline Urea $(\mathrm{mg} / \mathrm{dL})$ & 68.50 & 39.87 \\
\hline Creatinine $(\mathrm{mg} / \mathrm{dL})$ & 2.01 & 0.96 \\
\hline Triglycerides $(\mathrm{mg} / \mathrm{dL})$ & 277.1 & 268.40 \\
\hline Serum proteins $(\mathrm{g} / \mathrm{dL})$ & 6.28 & 0.34 \\
\hline Serum amylase (IU/L) & 185.73 & 410.50 \\
\hline Temperature $\left(\mathrm{C}^{\mathrm{o}}\right)$ & 36.72 & 1.83 \\
\hline Systolic blood pressure $(\mathrm{mmHg})$ & 145.45 & 20.24 \\
\hline Diastolic blood pressure $(\mathrm{mmHg})$ & 81.29 & 15.61 \\
\hline Urinary ketone bodies (mg/dL) & 106.20 & 59.47 \\
\hline
\end{tabular}

Positive correlation could be observed during statistical analysis between the $p \mathrm{H}$ and base excess (Fig. 1), and also between the $\mathrm{pH}$ and bicarbonate values (Fig. 2). Negative correlation could be found between triglyceridemia (mg/dL) and BMI $\left(\mathrm{kg} / \mathrm{m}^{2}\right)$ values $(\mathrm{r}=-0.6403, \mathrm{p}=0.0461)$, and a tendency for negative correlation between $p \mathrm{H}$ and lactic acid $(\mathrm{mg} / \mathrm{dL})$ concentration $(\mathrm{r}=-0.3299, \mathrm{p}=0.0652)$. 


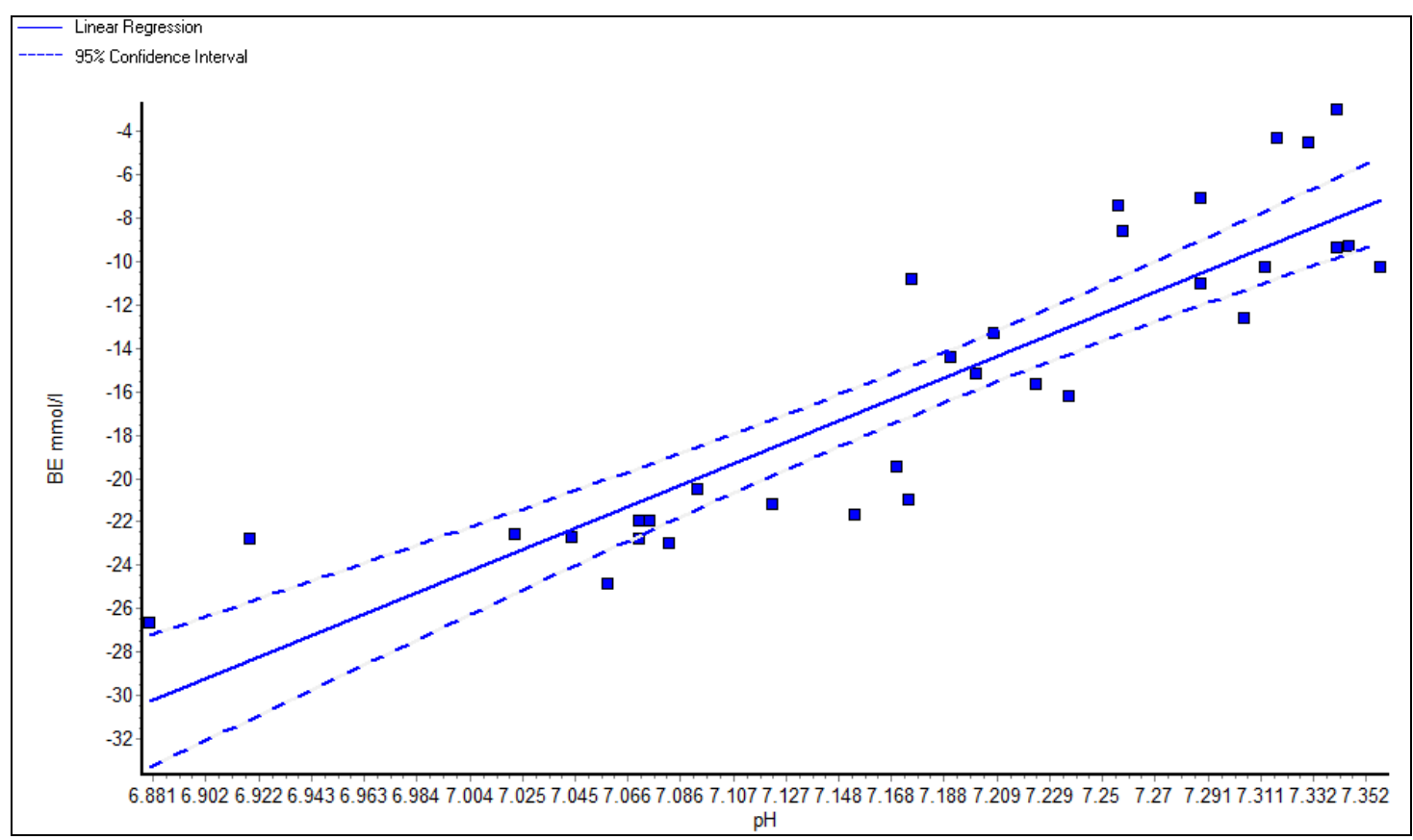

Fig. 1. Correlation between $\mathrm{pH}$ and base excess values ( $\mathrm{r}=0.8901, \mathrm{p}<0.0001)$

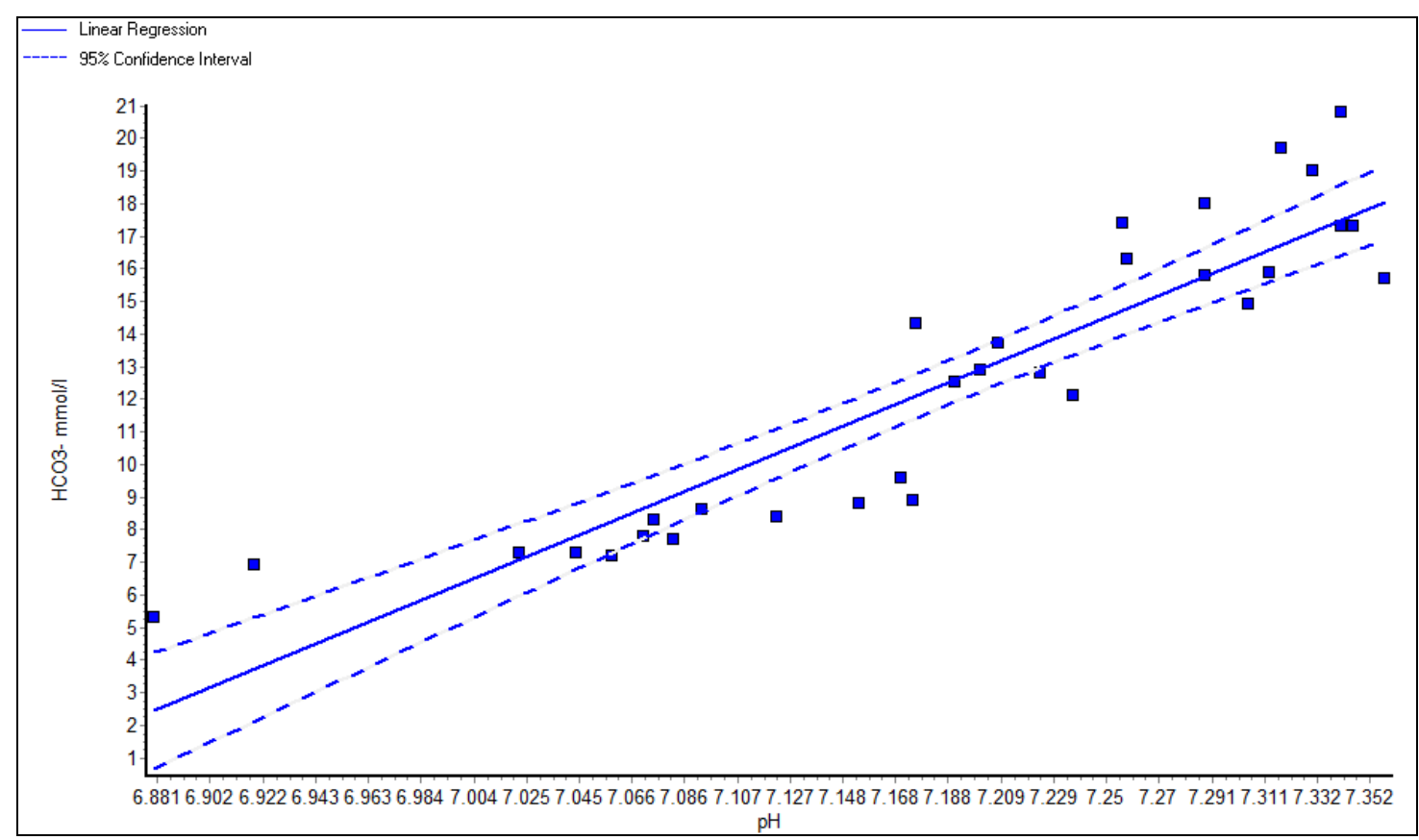

Fig. 2. Correlation between $p \mathrm{H}$ and bicarbonate values $(\mathrm{r}=0.9137, \mathrm{p}<0.0001)$

The distribution of serum glucose values can be observed in Figure 3, and the distribution of $p \mathrm{H}$ results in Figure 4. The majority of the patients $(56.3 \%$ ) presented glycemia between $400-700 \mathrm{mg} / \mathrm{dL}$ and $p \mathrm{H}$ under 7.21 , revealing severe ketoacidotic state. $62.5 \%$ showed decreased serum sodium levels, $15.6 \%$ presented increased serum potassium concentration and the same percentage had hypopotassemia.

All patients in diabetic ketoacidosis presented clinical or paraclinical (elevated serum urea and/or creatinine) signs of dehydration. Hypoproteinemia was present in $46 \%$ and hypertriglyceridemia in $60 \%$ of the patients. 

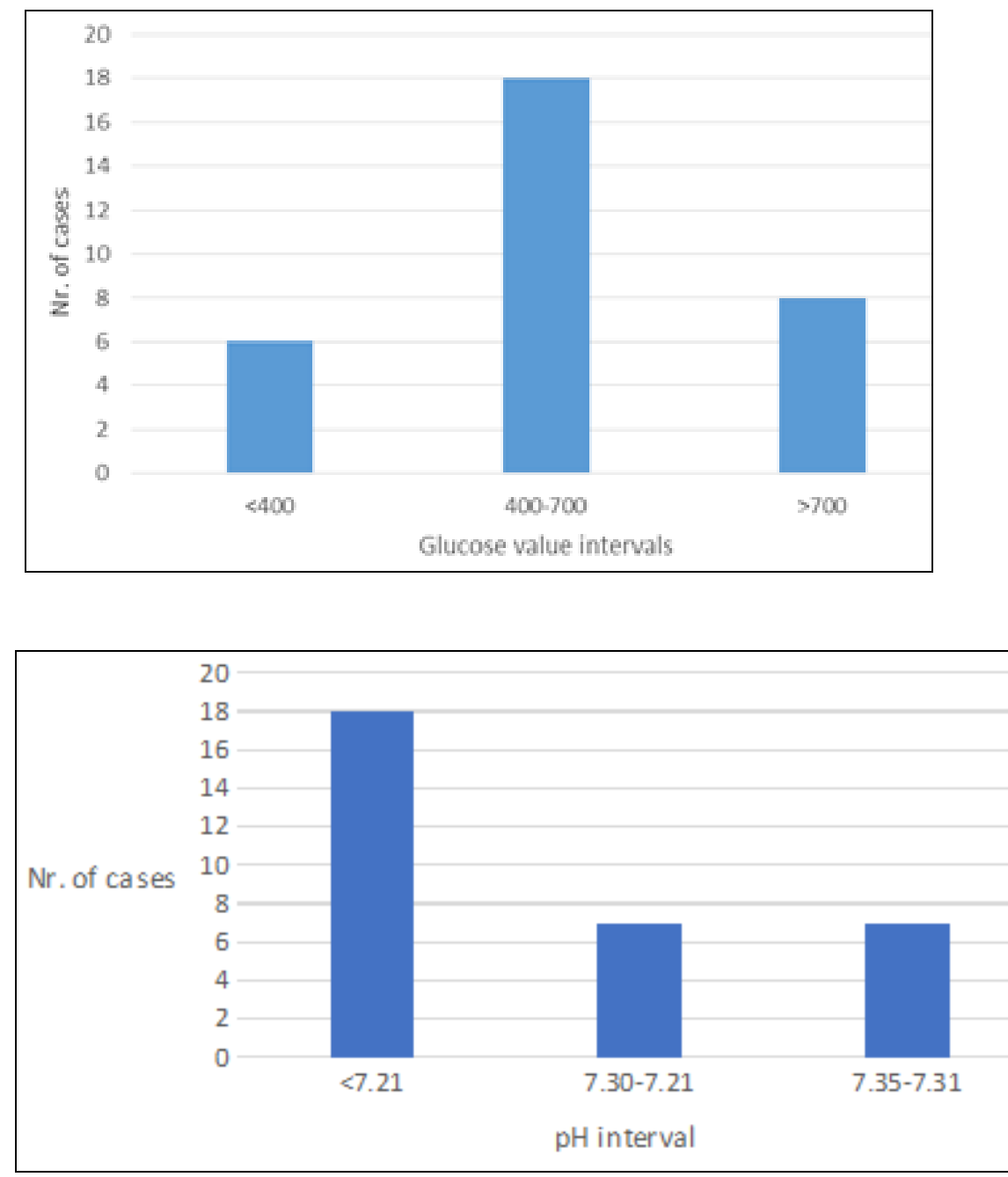

Fig. 3. Distribution of serum glucose values $(\mathrm{mg} / \mathrm{dL})$ in the patients with diabetic ketoacidosis

From studied ketoacidotic patients $68.8 \%$ presented leukocytosis, and $28.1 \%$ had fever or subfebrility when admitted to the hospital. $25 \%$ of the patients presented elevated serum amylase activity (exceeding $100 \mathrm{IU} / \mathrm{L}$ ), and $28.1 \%$ were documented for chronic alcohol abuse.

Based on the urine test strip results we can observe that $71.9 \%$ of the patients had pathological compounds related to possible urinary tract infections (hematuria, leukocyturia). $90.6 \%$ of the patients presented ketonuria, 56.3\% of the subjects having $150 \mathrm{mg} / \mathrm{dL}$ ketone bodies in the urine. $93.8 \%$ of the studied patients presented glucosuria, $71.9 \%$ of the subjects having 500-1000 mg/dL glucose in the urine samples when admitted to the hospital.

The high frequency of patients having leukocytosis and elevated body temperature emphasize the presence of infectious diseases as triggers of the diabetic ketoacidotic state in several patients. Respiratory diseases and pancreatitis are among the most frequent infectious diseases in the background of diabetic ketoacidosis, but decreased insulin doses, cardiovascular diseases such as stroke, myocardial infarction or certain medication such as steroid treatment could also be triggers for this state [11]. The high incidence of patients having increased amylase activity indicates the second one as quite frequent in our study group, alcohol abuse and hypertriglyceridemia [7] being closely related to this condition.

In diabetic ketoacidosis, the concentration of electrolytes and metabolites should be evaluated in dinamics, because the treatment of the patients with diabetic ketoacidosis can have a major impact on the laboratory parameters. The metabolism of all major biomolecules is affected in diabetic ketoacidosis: carbohydrate, protein and lipid metabolic pathways are disturbed. Medication of diabetic subjects should always been adapted to the current needs of the patients [12]. Acidosis contributes to hyperpotassemia, administration of glucose and insulin lowers the level of potassium [9].

\section{Conclusions}

Several important metabolic and hydroelectrolytic disturbances could be revealed in the studied patients presenting diabetic ketoacidosis. Different types of infectious diseases are the most common triggers of metabolic imbalance in these subjects. Laboratory investigations have an important contribution to the diagnosis and follow-up of these cases which continue to represent a major complication of diabetes nowadays. 


\section{References}

1BOITOR GC, CORMOS G, STETIU A, STEF L, ORMENISAN A, MARIS M, COMANEANU RM, CERNUSCA MITARIU M, Associating certain salivary parameters with oral health for a group of patients with type II diabetes mellitus, Rev. Chim.(Bucharest), 67, no. 11, 2016,

p. 2314-2317

2.MOTA, M., POPA, S.G., MOTA, E., MITREA, A. et al. Prevalence of diabetes mellitus and prediabetes in the adult Romanian population: PREDATORR study. J Diabetes. 2016, 8(3), p.336-44.

3.NEAGOE, R.M., MUREȘAN, M., BANCU, S. et al. Results of Laparoscopic Sleeve Gastrectomy - 5-Year Follow Up Study in an Eastern European Emerging Bariatric Center, Obes. Surg., 27, 2017, p. 983-989

4.TILINCA, M.C., PAL, S., PREG, Z., et al. The Relationship of Metabolic and Endocrine Parameters with Associated Diseases in Diabetes Mellitus, Rev. Chim.(Bucharest), 69, no. 5, 2018, p. 1288-91

5.MENDEZ Y., SURANI S., VARON J. Diabetic ketoacidosis: Treatment in the intensive care unit or general medical/surgical ward? World J. Diabetes, 8, nr. 2, 2017, p. 40-44

6.SAMASCA G., SUR G., LUPAN I., et al. Celiac disease as an autoimmune condition, Centr. Eur. J. Immunol., 39, nr. 3, p. 396-399

7.SHAIKH B.H., SOHAIB M., ALSHANTTI R. et al. Diabetic Ketoacidosis and the Domino Effect, Am. J. Case Rep., 19, 2018, p. 1342-1344

8.PATEL M.P., AHMED A., GUNAPALAN T. et al. Use of sodium bicarbonate and blood gas monitoring in diabetic ketoacidosis: A review, World J. Diabetes, 9, nr. 11, 2018, p. 199-205

9.TAZLAVAN T., COJOCARU V., MORARU E. Management of diabetic ketoacidosis, Arta Medica, 1, nr. 22, 2007, p. 39-41

10.ISLAM T., SHERANI K., SURANI S. Guidelines and controversies in the management of diabetic ketoacidosis - A mini-review, World J. Diabetes, 9, nr. 12, 2018, p. 226-229

11.JEHLE D., JOHNSON D., MARTEL T. et al. Severe diabetic ketoacidosis presenting with negative serum ketones, Am. J. Emerg. Med., 35, 2017, p. 196.e3-e5

12.PELIN A.M., GAVAT C.C., BALAN G. et al. Pharmacological Principles Used in Patient Monitoring with Type 2 Diabetes, Rev. Chim.(Bucharest), 68, no. 2, 2017, p. 378-383

Manuscript received: 10.01 .2019 